Caligrama, Belo Horizonte, v. 24, n. 1, p. 143-155, 2019

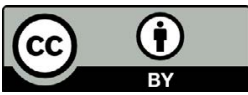

\title{
Marquês de Sade: crime, destruição e excesso
}

\section{Marquis de Sade: Crime, Destruction and Excess}

\author{
Cátia Vieira \\ Universidade do Minho, Braga / Portugal \\ cati.sousavieira@gmail.com
}

Resumo: O presente artigo tem como objetivo primordial investigar a ligação entre o erotismo e a morte, que abrange questões como o crime, a destruição e o excesso, na obra sadiana. Marquês de Sade, senhor dos sádicos, estabeleceu a vida como um mero meio para a obtenção do prazer máximo. E esse prazer, segundo o autor francês, apenas se faz sentir de forma apoteótica quando destrói a vida. Assim, gozar é sinónimo de ver destruir, de abraçar e de satisfazer a morte. Além de destruir, torna-se imprescindível violar, violentar e matar sem freios, sem imposições morais. Para a elaboração deste estudo, recorreu-se não só à produção literária de Marquês de Sade, mas também a textos teórico-críticos, que focam as noções de erotismo, morte e sadismo.

Palavras-Chave: Marquês de Sade; sadismo; crime; destruição; excesso.

Abstract: This article investigates possible relations between eroticism and death, which cover issues such as crime, destruction and excess in the Sadeian work. Marquis de Sade, master of the sadists, envisioned life as a mere means for obtaining pleasure. And this pleasure, according to the French author, is only felt when life is destroyed. Thus, to enjoy is to destroy, furthermore, it is to embrace and to serve death. Besides destruction, Sade proposes that it becomes imperative to violate, rape and kill without limits, without moral impositions. Not only the literary production of Marquis de Sade proved to be paramount to this research, but also theoretical texts which focus on eroticism, death and sadism.

Keywords: Marquis de Sade; sadism; crime; destruction; excess. 
Marquês de Sade colidiu com a mentalidade do leitor do século XVIII e parece continuar a perturbar quem o lê nos nossos tempos. Escrevendo o excesso, a transgressão, a destruição e uma ânsia voraz em aniquilar seres, sistemas e princípios, Sade foi apelidado como o "escritor terrorista" por Alexandrian (1991, p. 231). O autor libertino compreendeu que a literatura não institui limites e, por conseguinte, serviu-se da palavra para destruir o mundo como o conhecemos e criar uma nova sociedade, que acarreta novos paradigmas. Perante esses hinos à libertinagem, observamos, contudo, que, se o universo da palavra é um universo livre, a vida - com as suas normas e princípios - não o é. Confrontados com a obra de Sade e os seus homens soberanos, percebemos que o excesso praticado na ausência de limites e regras conduz-nos à total destruição e à impossibilidade de vida. Conduz-nos, portanto, a uma inevitável morte. Alexandrian, em sua História da literatura erótica, reflete sobre a diferenciação necessária entre o imaginável e o realizável. Assim, admiramos a obra de Sade pela sua imaginação radical, que levou o excesso ao expoente, transgrediu qualquer proibição, devorou e aniquilou o mundo como o conhecemos. Por meio da linguagem, ele criou e justificou uma sociedade alternativa que protege apenas aqueles que são soberanos. Essa é uma sociedade que não permite limites, impondo o terror. Por conseguinte, a "vítima" está sujeita ao castigo, à sua aniquilação, à morte. Contudo, como reitera Alexandrian (1991, p. 234), a obra de Sade, apesar de nos conduzir ao limiar do nosso imaginário, não poderá ser realizável para que possamos preservar a vida.

Referimos previamente uma sociedade alternativa em que impera a soberania da libertinagem. Assim, a questão coloca-se: quem são os libertinos de Sade? Em primeiro lugar, torna-se premente assinalar o seu traço distintivo: o viés sádico. O homem soberano elege a inflição de dor e a degradação do outro como fonte primária de prazer. Não há qualquer possibilidade de deleite na ausência de violência, de transgressão e de corrupção do outro. Na verdade, encarar o outro como aquele que lhe é submisso não é satisfatório. Torna-se imprescindível destruí-lo, votá-lo à humilhação, aniquilá-lo até esgotar todos os laivos de vida. Assim, o libertino inala a morte e o excesso através da dilapidação da sua vítima:

Todos os heróis pensam que o verdadeiro prazer é a dor; desejando sofrer durante o gozo alguns fazem-se chicotear ou molestar durante o acto sexual. Mas, como não querem ir até à autodestruição, preferem causar dor nos outros. Quanto maior for, mais perfeito será o prazer. (ALEXANDRIAN, 1991, p.230) 
Contudo, o deleite do sádico não advém da experiência medíocre, mas do puro espetáculo do mal e esse é um processo caprichoso e oscilante. Por conseguinte, atingir o orgasmo transforma-se numa tarefa árdua, que requer mais esforço dos sentidos e da imaginação e, inevitavelmente, mais destruição. Ademais - ainda que para o libertino, o amor exclusivo se assuma como uma espécie de prisão que lhe renega os prazeres e o restringe a um só ser - deveremos assinalar que, para aquele que se entrega à libertinagem e ao sadismo, o outro é também fulcral para a obtenção do gozo. Assim, o libertino depende necessariamente de sua vítima. No entanto, sua prisão não se resume apenas à presença de um mártir, mas também à constante pressão em aumentar e aperfeiçoar o leque de sua crueldade. Em suma, o homem soberano aniquilará o outro, sem quaisquer limites, na busca do seu tão inestimável prazer. Angela Carter, na obra The Sadeian Woman, caracterizou o libertino como um ser que exala vontades e atitudes demoníacas, que fareja a destruição e, jubilosamente, a executa:

O erotismo de Sade, com o seu estilo trágico, as suas ostentações, as suas procissões, os seus sacrifícios, as suas máscaras e trajes, preserva algo de demoníaco do homem primitivo. Os libertinos são, de facto, como homens possuídos por demónios. Os seus orgasmos são como visitações dos deuses do vudu, destruindo, aterrorizando. ${ }^{1}$ (CARTER, 2006, p.175, tradução nossa)

Os libertinos da obra sadiana, considerados os senhores do trono, regem-se exclusivamente pelo mal. Somente a consciencialização da perversidade e da crueldade espoletará o desejo que, consequentemente, conduzirá à obtenção de prazer. Torna-se oportuno, contudo, constatar que o regozijo do homem soberano não reside no momento orgástico, mas na transgressão das regras e limites impostos e na corrupção e destruição daquele que chora o seu destino. Assim, o homem sadiano rejubila-se perante o sofrimento do outro, porque não é o seu; deleitase sabendo que a sua felicidade se impõe à miséria do outro. Instalase, por conseguinte, uma hierarquia que privilegia a brutalidade e a desumanidade, aniquilando a possibilidade de virtude e benevolência. Esse é o mundo dos sádicos. Ademais, se é o mal que conduz a ação

\footnotetext{
${ }^{1}$ No original: "Sade's eroticism, with its tragic style, its displays, its cortèges, its sacrifices, its masks and costumes, preserves something of the demonology of the primitive man. The libertines are indeed like men possessed by demons. Their orgasms are like the visitation of the gods of Voodoo, annihilating, appalling".
} 
do libertino, é ele também o gerador da euforia sexual. Assim, não é o objeto que seduz o homem sadiano, mas sim a ideia de perpetuar o mal, a ânsia em manchar a vítima:

[...] e estou perfeitamente convencido de que não é o objecto da libertinagem que nos excita, mas sim a ideia do mal e que, por consequência, é mercê do mal que ganhamos tesão e não mercê do objecto, de tal guisa que, se esse objecto fosse privado da possibilidade de nos levar a praticar o mal, não nos provocaria qualquer tesão. ${ }^{2}$ (SADE, 2007, p.217)

Se a libertinagem pressupõe o poder de um, pressupõe de forma inevitável a submissão de outro. Consequentemente, ao longo da obra de Sade, confrontamo-nos com inúmeras vítimas, que são primordialmente do sexo feminino. Antes de refletirmos sobre a questão da misoginia - que acusa uma centralidade inegável no texto sadiano - deveremos salientar que os libertinos optam por desposar mulheres de modo a torná-las suas escravas, porque, na condição de esposas, a sua submissão é intensificada, o que estimula mais o desejo do homem soberano. Além disso, a transgressão é ainda maior quando corrompe uma mulher a quem fez votos matrimoniais e religiosos. Assim, aquele que é desejado é aquele que é submisso, como afirmou Angela Carter (2006, p. 88, tradução nossa): "Existir na voz passiva é morrer na voz passiva - isto é, ser morta". ${ }^{3}$

Como referimos anteriormente, o libertino de Sade perpetua o mal, mas renega sobretudo a prática do bem. Confrontamo-nos com homens que desconhecem termos como benevolência, misericórdia ou culpabilidade. Aqueles que se devotam à libertinagem perenizam o exercício do mal apesar de reconhecerem o sofrimento imposto ao outro. Não há espaço para as leis ou para os preceitos morais que condenam a destruição, porque o que impera é o deleite do libertino, que se distingue do prazer do homem comum. A única lei a que esses homens soberanos respondem é a lei da volúpia. Surge, então, a morte do sistema moral e social como o conhecemos.

A ausência de compaixão a que nos temos referido vincula-se ao conceito de apatia, pensado por Georges Bataille, em sua obra O erotismo.

\footnotetext{
${ }^{2}$ No original: “[...] et je suis parfaitement sûr que ce n'est pas l'objet du libertinage qui nos anime, mais l'idée du mal ; qu'en conséquence, c'est pour le mal seul qu'on bande et non pas pour l'objet, en telle sorte que si cet objet était dénué de la possibilité de nous faire faire le mal nous ne banderions plus pour lui." (SADE, 1975, p.241).

${ }^{3}$ No original: "To exist in the passive case is to die in the passive case - that is, to be killed."
} 
Sade partiu da premissa de que o homem emergiu de um cerne de inveja, de solidão e de crueldade, erguendo-se como um déspota que busca incansável e impiedosamente a satisfação dos seus desejos e volúpias - mesmo que obscuros -, ainda que isso signifique a destruição do outro. Destarte, o homem libertino não pondera renegar a sua sede em detrimento do bemestar de outras pessoas, porque é algo que o excede. Vejamos um exemplo, no seguinte excerto de Justine ou les malheurs de la vertu:

O prazer deleita-o, é algo seu, ao passo que o efeito do crime não o afecta, é algo de exterior a ele; ora eu só pergunto qual é o homem de juízo que não prefere o que o deleita ao que lhe é estranho, quem é que não consente em praticar esse ato estranho, que em nada o aflige, com vista a obter outra coisa que lhe dá uma sensação agradável? ${ }^{4}$ (SADE, 2015b, p.40)

Como assinala Bataille (1988), ao considerarmos e obedecermos a outros indivíduos, respeitando desse modo as normas sociais, completamos um ciclo de servidões, em que impera o respeito ao outro, mas se aniquila a satisfação dos nossos desejos mais íntimos, destruindo a possibilidade de soberania. Sade, que condena veementemente esse sistema, arruína-o e constrói uma sociedade em que as vontades do outro não têm lugar, negando a sua individualidade. Os libertinos sadianos concentram toda sua potência e energia em comprazerem-se em seu próprio deleite, alienando as aspirações do que lhe é exterior. Essa é a sua soberania. Esses homens reconhecem que são seres isolados e abraçam esse conhecimento (BATAILLE, 1988, p.151). Ademais, aquele que se entrega à libertinagem rejeita ferverosamente interpretar sua conduta como fruto de doença, visto ser a concretização das ânsias de uma natureza destruidora e assassina. Assim, o homem sadiano aventura-se e materializa todas as suas fantasias, aniquilando vontades secundárias, porque cumpre supostamente os desígnios desse elemento superior que é a natureza.

Ao refletirmos sobre o homem soberano de Sade, refletimos inevitavelmente sobre o conceito de excesso. Como destacámos

\footnotetext{
${ }^{4}$ No original: "La jouissance le flatte, elle est en lui, l'effet du crime ne l'affecte pas, il est hors de lui ; or, je demande quel est l'homme raisonnable qui ne préférera pas ce qui le délecte à ce qui lui est étranger, et qui ne consentira pas à commettre cette chose étrangère dont il ne ressent rien de fâcheux, pour se procurer celle dont il est agréablement ému?" (SADE, 1973, p.70).
} 
anteriormente, levar o excesso ao expoente é aniquilar o princípio de vida; é dar lugar à morte. Antes de mais, torna-se premente assinalar que nos romances sadianos a relação sexual não deverá proporcionar prazer de forma igualitária. Como o autor afirmou:

É perfeitamente inútil que o prazer, para ser vivo, tenha de ser repartido; e para que essa espécie de prazer seja tão excitante quanto ele é susceptível de ser, torna-se essencial que o homem goze à custa da mulher, que dela extraia (sem se importar com a sensação que ela possa experimentar) tudo o que possa incrementar a volúpia que deseja gozar. ${ }^{5}$ (SADE, 2015b, p.151)

Para o libertino, abraçar uma relação igualitária seria aniquilar a transgressão e, consequentemente, a violência que conduz à morte princípios fundamentais à erupção de prazer do sádico.

O libertino de Sade - que tende a isolar-se em locais remotos e do próprio sistema social - renega quaisquer limites ao seu desregramento. Pelo contrário, a tentativa (ainda que falhada) de impedir ou proibir as aspirações libertinas do homem soberano conduz meramente a sua incrementação. Nada contém a libertinagem. Os excessos aprazem ao homem sadiano e o que é repugnante é objeto de desejo. Se as barreiras e os freios intensificam o prazer do libertino, a impunidade que detém com a sua soberania é a explosão de deleite. Após concretizarem horrores inelutáveis, surge uma ânsia embriagada de os agravarem. O próprio corpo da vítima é campo aberto para a perpetração de horrores, sendo molestado, servindo assim todos e quaisquer desejos do "mestre".

Em $O$ erotismo, Bataille defendeu que o tempo do trabalho e das normas sociais protege as relações humanas e a possibilidade de vida em sociedade. Na sociedade sadiana, que se entrega exclusivamente ao excesso e renega a razão, o perigo de aniquilação do princípio de vida é uma constante. Roland Barthes, em Sade, Fourier, Loyola (1971), enfatizou que a vítima tenta de modo desesperado preservar os princípios que perfazem o tempo do trabalho, protegendo a lei e os princípios morais. Atentemos, por exemplo, em Justine, que defende incessantemente a virtude e condena os

\footnotetext{
${ }^{5}$ No original: "Il est parfaitement inutile qu'une jouissance soit partagée pour être vive ; [...] il est au contraire très essentiel que l'homme ne jouisse qu'aux dépens de la femme, qu'il prenne d'elle (quelque sensation qu'elle en éprouve) tout ce qui peut donner de l'accroissement à la volupté dont il veut jouir." (SADE, 1973, p.202).
} 
horrores perpetrados pelo homem soberano, impedindo que o paradigma moral se altere ou se funde em conceitos libertinos. Antagonicamente, aquele que se entrega à libertinagem tenta não só destruir a vítima, corrompendo as leis morais, mas aniquilar aquilo que considera um preconceito da língua. O libertino pretende, por conseguinte, reunir as significações de conceitos distintos, eliminando a sua carga pejorativa, enquanto a vítima, visando salvaguardar os princípios de vida, esforça-se por manter as dicotomias (BARTHES, 1971, p.156).

Ainda que o excesso se verifique sobretudo nas aspirações sexuais dos libertinos, a sua nutrição revela a mesma imoderação e opulência. Porém, e seguindo ainda os pensamentos de Roland Barthes (1971, p.23), a alimentação desregrada não é somente uma mera fonte de prazer, mas também é motor de restauração, de envenenamento e proporciona a evacuação, sendo que a luxúria é notoriamente o fio que une os desejos libertinos.

Se o excesso e a transgressão dominam a conduta do homem sadiano, o crime é indispensável para a rejubilação e euforia total. Desse modo, a beleza da mulher ou do homem que o libertino deseja ou ainda a volúpia que busca satisfazer não são as razões que determinam a inflamação do mestre. O que provocará infalivelmente o auge do prazer é a perpetração de um crime, sendo que o maior de todos é o homicídio. Cometer um crime é transgredir, é violentar conscientemente, é exceder. Logo, de modo inevitável, o crime é o apogeu da libertinagem. O homem soberano não necessita de uma razão para matar; basta desejá-lo. Segundo Sade, a morte é o propulsionador absoluto do deleite, vinculando profundamente o erotismo à aniquilação de vida. E, nas palavras do autor libertino, conciliar-nos-emos apenas com a morte quando a associarmos a uma ideia que exale os princípios da libertinagem. Assim, esta é a proposição da vida libertina:

[...] Sentirás vir a morte no meio de inexprimíveis sensações de prazer; a compressão que esta corda operar sobre a massa dos teus nervos inflamar-te-á os órgãos da volúpia; o efeito é certo; se todas as pessoas condenadas a este suplício soubessem o gozo que tal morte produz, em vez de recearem ser castigadas pelos seus crimes tratariam de os cometer mais vezes e com mais segurança. ${ }^{6}$ (SADE, 2015b, p.220)

\footnotetext{
${ }^{6}$ No original: “[...] tu ne sentiras la mort que par d'inexprimables sensations de plaisir; la compression que cette corde opérera sur la masse de tes nerfs va mettre en feu les organes de la volupté ; c'est une effet certain ; si tous les gens condamnés à ce supplice savaient
} 
Temos demonstrado que o excesso é essencial para que o homem libertino se compraza. Porém, deveremos assinalar que a violência e a excentricidade não se verificam somente nas volúpias que concretizam, mas também no objeto que desejam. Por conseguinte, o homem soberano deseja a elegância, a graça e a perfeição para que possa violentar e incluir uma mancha inconfundível, arruinando a pureza. Por outro lado, procura a imundície e a obscenidade, pois o cenário caótico e pútrido aproxima-o ainda mais da destruição, do nada, da morte. O corpo compreendido pelo libertino como deformado e monstruoso - como o das cegas, das pernetas, das desdentadas ou flageladas - seduz o libertino, porque, assim como aqueles repletos de graciosidade, representa um extremo, o excesso. Porém, apesar de em pólos opostos, algo aguarda silenciosa e lentamente essas mulheres: a morte. Atentemos de novo nas palavras de Angela Carter (2006, p.87-88, tradução nossa):

[...] o entusiasmo sexual que eles [os libertinos de The Hundred and Twenty Days at Sodom] manifestam pelos monstros velhos, enrugados e ulcerados é um reverso irónico da veneração pela beleza física; a fealdade humana ao expoente é um fenómeno tão extraordinário quanto o da beleza e é um fenómeno do mesmo género, um de excesso. [...] $\mathrm{E}$, como as meninas e meninos bonitos, as mulheres velhas e monstruosas são torturadas e assassinadas; elas deverão pagar o preço por serem desejáveis assim que forem desejadas. ${ }^{7}$

Assim, os libertinos assassinam o objeto, porque o desejam. Para a erupção de tamanha transgressão e violência, torna-se impreterível o isolamento da sociedade sadiana para que possa proteger a libertinagem dos indivíduos do mundo real que a castigaria e puniria (BARTHES, 1971, p.20). Pensemos no castelo de Silling na obra Les 120 journées de Sodome, considerado impenetrável e inescapável. Ademais, os cenários

dans quelle ivresse il fait mourir, moins effrayés de cette punition de leurs crimes, ils les commettraient plus souvent et avec bien plus d'assurance." (SADE, 1973, p.284).

${ }^{7}$ No original: "[...] the sexual enthusiasm they [the libertines in The Hundred and Twenty Days at Sodom] exhibit for the wrinkled and ulcerated old monsters is an ironic reversal of the veneration of physical beauty; human ugliness as its most extreme is as extraordinary a phenomenon as beauty and a phenomenon of the same kind, one of excess. [...] And, like the beautiful girls and boys, the monstrous old women are tortured and killed; they must pay the high price of their own desirability as soon as they are desired." 
onde decorrem os molestamentos, as relações sexuais e os rituais orgiásticos exalam a morte absoluta, sendo constantemente descritos como funestos ou como uma cloaca.

Mas a morte participa também na linguagem que brota na relação sexual. Madame de Saint-Age, em La Philosophie dans le boudoir, revela: "Ai, que incrível excesso de volúpia, ai!... Ai, que morro!" (SADE, 2015a, p.94). Assim, o excesso e a violência que irrompem na união sexual conduzem o indivíduo a uma aniquilação do ser, esvaindose a força e a consciência. Confrontados com essa obra publicada em 1795, na qual Dolmancé e Madame de Saint-Age apresentam a escola da libertinagem a Eugénie, permitindo-lhe descobrir a sua sexualidade e os seus desejos mais obscenos, poderíamos, quiçá, associar Marquês de Sade a noções feministas. Aliás, Angela Carter, entre outros autores e críticos, considera Sade como um pensador vanguardista no que concerne à liberdade sexual feminina. Segundo a autora: "A obra de Sade [...] é particularmente significativa para as mulheres pela sua recusa em perspetivar a sexualidade feminina segundo a sua função reprodutora, uma recusa tão incomum no final do século XVIII como agora"" (CARTER, 2006, p.1, tradução nossa).

Porém, perante a misoginia gritante da obra sadiana, pensamos que afirmar Sade enquanto libertador da sexualidade feminina é uma asserção talvez excessiva. O libertino de Sade, que considera o corpo feminino repugnante, evidencia não só o seu asco, mas o seu ódio à mulher. O sexo feminino é considerado pelo homem soberano como de cariz inferior e inútil, votando a mulher a humilhações colossais e esgotando-lhe a essência, aquilo que tem de mais íntimo. Por conseguinte, aquele que se entrega à libertinagem, enquanto homem sádico, deleita-se na aniquilação e destruição do corpo e, acima de tudo, do eu feminino.

Numa sociedade dominada por homens soberanos, a mulher é a vil serva que terá de prever, desvendar e cumprir todos os desígnios e aspirações do seu mestre. Ainda que haja personagens femininas a acusar o sadismo no seu cerne - como as historiadoras de Les 120

\footnotetext{
${ }^{8}$ No original: “Ahe! ahe! ahe! foutre!... foutre!... quel incroyable excès de volupté!... Je me meurs!" (SADE, 1976, p.155).

${ }^{9}$ No original: "Sade's work [...] is of particular significance to women because of his refusal to see female sexuality in relation to its reproductive function, a refusal as unusual in the late eighteenth century as it is now."
} 
journées de Sodome -, a condição do sexo feminino é degradante, fatal e imperiosamente inferior ao do homem soberano: "[...] por todo lado, numa palavra, vejo as mulheres humilhadas, molestadas, sacrificadas à superstição dos padres, à barbárie dos maridos ou aos caprichos dos libertinos"10 (SADE, 2015b, p.195).

No sistema social erigido pelos sádicos, a mulher que preserva a graciosidade, a pureza e a elegância incita à destruição e à corrupção de sua castidade. As esposas dos libertinos do castelo de Silling, que exalavam candura e virtude, apresentaram-se como o objeto perfeito para se perpetrar a mancha do sádico, a mancha da destruição. Desse modo, o sádico procura e devasta aquilo que a mulher mais resguarda e mais estima. Atentemos, ainda, em Justine - personagem que se vangloria da sua indiferença pelos prazeres carnais - que é molestada e lesada continuamente. Como assinalou Angela Carter (2006, p.56), não é a violação que essa personagem teme, visto ser um ato inculposo, mas a sua sedução e participação em algum momento, porque sua virtude reside na ausência de prazer sexual ou de desejo pelo outro. Negando prostituir-se ou envolver-se no crime, Justine é impelida forçosamente para o mundo libertino, sendo uma vítima desse desregramento. A sociedade sadiana não concede lugar à virtude; ela extirpa-a. Assim, aquelas que preservam sua honra e graciosidade são degradadas e humilhadas, encontrando-se à mercê do mestre:

A princesa do conto de fadas é reduzida à condição de prostituta na sarjeta [...]. Mas, tendo em conta que a princesa ainda se perspetiva enquanto princesa ao invés de se encarar enquanto prostituta, ela foi realmente degradada. Os libertinos mostram-lhe que as características que a tornam sagrada podem ser-lhe facilmente retiradas. Eles atiram-na para a cama, de rosto para baixo, e concentram as suas atenções no seu traseiro, uma parte do seu corpo que a mesura sempre ignorou. Eles obrigam-na a realizar publicamente atividades escatológicas que ela sempre conduziu em privado, como se de uma atividade degradante se tratasse uma atividade demasiado humana, demasiado vulgar para ser

\footnotetext{
${ }^{10}$ No original: “[...] partout, en un mot, je le répète, partout je vois les femmes humiliées, molestées, partout sacrifiées à la superstition des prêtes, à la barbarie des époux, ou aux caprices des libertins.” (SADE, 1973, p.254).
} 
publicamente reconhecida por uma criatura tão rara quanto ela ${ }^{11}$ (CARTER, 2006, p.85, tradução nossa).

Perante a "lubricidade destrutiva" (SADE, 1973, p.207, tradução nossa) do libertino, resta somente a aniquilação do eu feminino, do eu da vítima. $\mathrm{O}$ homem soberano requer uma submissão e uma abnegação absolutas do ser que domina. Essa servidão conduz à morte do âmago, a um esvaziamento total do ser. Por outro lado, como referimos anteriormente, determinadas personagens da galeria feminina sadiana entregam-se a uma vida libertina de forma a minimizar a sua deterioração. Contudo, torna-se oportuno assinalar que a morte do ser feminino é uma constante, visto que há uma impossibilidade de sentir e ser inteiramente. A única solução é: “Aujourd'hui l'un, demain l'autre, il faut être putain, mon enfant, putain dans l'âme et dans le cœur" (SADE, 1975, p.144).

Confrontado com tamanha degradação feminina, o libertino deleita-se; impossibilitado de a concretizar, ele amaldiçoa. Busca incessantemente testemunhar não só a mancha que perpetra na vítima, mas aquela concedida por outros, e, desse modo se compraz. Acima de tudo, o homem soberano procura danificar a mulher, escondendo todos os vestígios da sua feminilidade, devido ao seu ódio e repugnância dela. Como defendeu Barthes (1971), o processo pelo qual se regem os libertinos é um paradoxo. O homem soberano oculta o sexo da mulher para que ela se assemelhe ao homem, a uma não mulher. No entanto, apesar da tentativa de disfarce, ela nunca poderá assumir-se como o outro, como homem. Não obstante o asco, o libertino parece eleger o sexo feminino como o seu predileto para a concretização das suas volúpias. Notemos que a relação sexual com a mulher é aquela que concede maiores possibilidades, o que é o mesmo que dizer maior transgressão e, consequentemente, maior deleite (BARTHES, 1971, p.128).

\footnotetext{
${ }^{11}$ No original: "The princess of the fairy tale is reduced to the condition of the whore in the gutter [...]. But, since the princess still retains her consciousness of herself as a princess rather than acquiring the self-possession of a whore, she has been truly degraded. The libertines show her that the qualities that made her precious can easily be stripped from her. They thrust her face-down on the bed and turn their attentions to her arse, that part of herself reverence has always particularly denied existed. They forced her to publicly perform excretory activity she has always conducted furtively, in private, as if it were as activity that in itself degraded her, an activity too human, too common to be publicly acknowledged by such a rare creature as herself."
} 
Referimos anteriormente que os libertinos privilegiam os espaços isolados e impenetráveis para a concretização de todas as obscenidades. As suas vítimas, após serem enclausuradas nos castelos ou mosteiros, são privadas da vida familiar, da vida social e de toda a sua individualidade. $\mathrm{O}$ vazio apodera-se delas e a sua única função é cumprir os deleites do libertino. Como fantasmas, elas aguardam uma morte que reconhecem como iminente. Perante a sua destruição, degradação e lenta aniquilação, a vítima sente o esvair de cada pulsão de vida. A sua submissão às aspirações da libertinagem é uma sentença de morte; é colocar-se "seio dos túmulos" (SADE, 1976, p.281, tradução nossa).

Os libertinos sadianos repudiam o sexo feminino, mas sobretudo a maternidade. Assinalámos anteriormente a preeminência do homicídio, mas deveremos reiterar que o matricídio é o momento que conduz o prazer ao expoente. $\mathrm{O}$ homem soberano abomina a figura maternal e tenta veementemente aniquilá-la do mundo que constrói. Rejeita, por conseguinte, qualquer apego à progenitora, porque não lhe reconhece qualquer valia. Segundo o sádico, engravidar é fruto de um ato exclusivamente egoísta cuja finalidade residiu no prazer carnal momentâneo. Ademais, ser mãe é dar vida a um ser que habitará num mundo trágico, caótico e déspota. $\mathrm{O}$ libertino de Sade busca vigorosamente aniquilar qualquer possibilidade de gestação e, consequentemente, queima o seu sémen. Ele destrói o ciclo de vida, concedendo somente lugar à morte.

Se o sádico legitima o matricídio, ele advoga o filicídio também. Destrói-se, portanto, todos os preceitos que visam à preservação e continuação da vida. $\mathrm{O}$ homem sadiano necessita desesperadamente arrancar o conceito de maternidade que reside na mente do outro, pois o oposto será "[a] morte do Pai, morte do Rei""12 (BRODRIBB, 1993, p.XX, tradução nossa). Apenas assim poderá criar uma nova sociedade que não prevê limitações morais e emocionais e que lhe atribui todo e qualquer poder. Além disso, como destacou Simone de Beauvoir (2015, p.280), a figura maternal relembra o homem da sua finitude e impotência perante um desígnio superior. Se o libertino não se pauta pela debilidade, torna-se premente violar, corromper e destruir o cerne maternal. Revela-se fundamental para a erupção da sociedade soberana a consciencialização da falta de lugar para a maternidade, a proteção e a virtude. $\mathrm{O}$ homem de Sade tudo destrói. Nasce o caos.

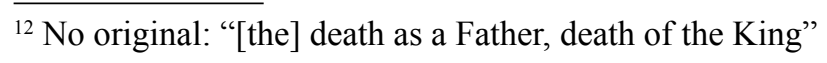




\section{Referências}

ALEXANDRIAN, S. História da literatura erótica. Tradução de Iva Delgado. Lisboa: Edição Livros do Brasil, 1991.

BARTHES, R. Sade, Fourier, Loyola. Paris: Éditions du Seuil, 1971.

BATAILLE, G. O erotismo. Tradução de João Bénard da Costa. Lisboa: Edições Antígona, 1988.

BEAUVOIR, S. O segundo sexo. Tradução de Sérgio Milliet. Lisboa: Quetzal Editores, 2015. v.1.

BRODRIBB, S. Nothing Mat(t)ers: a feminist critique of postmodernism. North Melbourne: Spinifex Press Pty, 1993.

CARTER, A. The Sadeian Woman: An Exercise in Cultural History. London: Virago Press, 2006.

SADE, D. A. F. Justine ou les malheurs de la vertu. Paris: Librairie Générale Française, 1973.

SADE, D. A. F. Les 120 journées de Sodome. Paris: Union Générale d'Éditions, 1975. v.1.

SADE, D.A.F. La Philosophie dans le boudoir. Paris: Gallimard, 1976.

SADE, M. A filosofia na alcova. Tradução de Manuel João Gomes. Vila do Conde: Verso da História, 2015a.

SADE, M. Justine ou os infortúnios da virtude. Tradução de Manuel João Gomes. Vila do Conde: Verso da História, 2015b.

SADE, M. Os cento e vinte dias de Sodoma. Tradução de Manuel João Gomes. Lisboa: Antígona, 2007.

Recebido em: 30 de abril de 2018. Aprovado em: 18 de agosto de 2018. 